\title{
ВЗАИМОСВЯЗЬ СИСТЕМНО-ДЕЯТЕЛЬНОСТНОГО И КОМПЕТЕНТНОСТНОГО ПОДХОДОВ В ОБРАЗОВАНИИ
}

\section{THE RELATIONSHIP OF SYSTEMIC AND EFFICIENCY APPROACHES IN EDUCATION \\ E. Karaseva \\ V. Karaseva}

Summary: This article provides a characteristic of a system-activity approach in education, describes approaches to interpretation of the concept, indicate the components and principles of its implementation, and also determines the relationship of systemic and competence approaches. The article discusses the role of the teacher as accompanying students in the learning process: preparation of instructions for students, creating various configurations for partnership, active participation in the discussion of student activities and creating situations. For self-control and self-esteem.

The author justifies the diversity and ambiguity of understanding the essence and meaning of a systemic activity approach in education.

Keywords: system and active approach; competence approach; principles of the system and active approach; components of the SIS-Dark and Active approach; The essence of the systemic and active approach.
Карасева Эльмира Миндыхатовна

К.n.н., дочент, Костанайский филиал ФГБОУ ВО «Челябинский государственный университет», Республика Казахстан, г. Костанай elmira_7@mail.ru

Карасева Венера Миндыхатовна

Костанайский региональный университет им. А. Байтурсынова, Республика Казахстан, г. Костанай

Аннотация: В данной статье дается характеристика системно-деятельностного подхода в образовании, описываются подходы к интерпретации концепции, указываются компоненты и принципы ее реализации, а также определяется взаимосвязь системно-деятельностного и компетентностного подходов. В статье рассматривается роль преподавателя как сопровождающего студентов в процессе обучения: подготовке инструкций для учащихся, создании различных конфигураций для партнерства, активном участии в обсуждении результатов студенческой деятельности и создании ситуаций. для самоконтроля и самооценки.

Автор обосновывает разнообразие и неоднозначность понимания сущности и смысла системно-деятельностного подхода в образовании.

Ключевые слова: системный и активный подход; компетентностный подход; принципы системного и активного подхода; компоненты системного и активного подхода; Суть системного и активного подхода.

зрения: как способствующий пониманию и приобретению новых знаний (когнитивный), и как один, закладывающий основу для дальнейшей работы (конструктивный). Каждый из этих аспектов имеет свой собственный путь прохождения.

При когнитивном подходе внешние выражения системы интерпретируются через ее внутренний механизм - ее состав и структуру [3].

При конструктивном подходе процесс проходит определенные этапы: проблемная ситуация, цель, функция, состав и структура, а также внешние условия.

Однако конструктивные и описательные стороны системного подхода неразрывно связаны и взаимно дополняют друг друга.

Деятельность - это целенаправленная система, нацеленная на конечный результат. Концепция системнодеятельностного подхода подразумевает, что результат может быть получен только при наличии обратной связи.

В совокупности с системным подходом деятельностный подход достигает значительной эффективности и 
методологически усиливается.

Способность студента учиться превращается в систему универсальных учебных действий [4].

Что должен выучить новичок, когда начинаешь учиться в вузе?

Суть системно-деятельностного подхода заключается в неразрывной связи требований, предъявляемых к выпускнику с последующей работой. Системно-деятельностный подход определяет алгоритм планирования квалификационных требований к выпускникам:

а) профессиональная деятельность специалиста рассматривается как система с условиями, обязательными для обучения студентов вуза;

б) определение конкретных квалификационных характеристик;

в) составление содержания образования.

Студент отрабатывает свои жизненные способности В то время, когда овладевает новыми знаниями не пассивно, а занимается самостоятельной учебно-познавательной деятельностью. Значительный потенциал для реализации деятельностного подхода лежит во внешкольной деятельности.

Федеральные государственные образовательные стандарты (ФГОС) основаны на системно-деятельностном подходе, который определяет три группы запросов на его разработку и реализацию:

1. Выражение целей образования как ожидаемых результатов деятельности студентов;

2. Построение начальной образовательной программы (ПКП);

3. Условия применения стандартов на практике.

В рамках системно-деятельностного подхода выработка компетенций человека превращается в реальность на основе схемы «компетенция - деятельность компетенция», а компетенция определяется как «знание в действии», выражающееся в способности использовать приобретенные знания. знания и навыки для достижения эффективных результатов в своей деятельности.

Компетентностный подход является основой новых образовательных стандартов; он ориентирует учебный процесс на выработку установленных компетенций, которые отражают готовность объекта функционировать в конкретных ситуациях [5].

Основная идея системно-деятельностного подхода заключается в том, что новейшие знания не предоставляются студентам в готовом виде. Студенты собирают его самостоятельно в процессе самостоятельной исследовательской деятельности. В то время как работа инструктора заключается в том, чтобы показать ученику на занятиях в классе, как получить эти знания, то есть облегчить правильную организацию их деятельности.

Преподаватель должен организовать учебный процесс, направленный на то, чтобы воспитать у ученика необходимость самостоятельно трансформировать учебный материал, и результатом такой трансформации должны стать новые знания, которые ученик получил самостоятельно [6].

Учебный материал служит образовательной средой, а не конечным знанием, которое приобретают студенты. Целью такой среды является достижение учениками целей обучения самостоятельно. Степень различия между результатами, полученными студентами в результате независимых исследований, и тем, что ожидается от них от преподавателя, заключается в степени эффективности обучения.

Роль преподавателя заключается не столько в обучении, сколько в сопровождении студентов в процессе обучения: подготовке инструкций для учащихся, создании различных конфигураций для партнерства, активном участии в обсуждении результатов студенческой деятельности и создании ситуаций. для самоконтроля и самооценки.

Системно-деятельностный подход усиливает особую значимость пути восприятия учеником своей деятельности. Без выяснения методов личного обучения, способов познания и мыслительной деятельности учащиеся не смогут самостоятельно осваивать новые знания [7].

Мотивация к учебной деятельности: преподаватели создают условия для возникновения у учащихся внутренней потребности в деятельности («Я хочу») и выделении зоны содержания («Я могу») [8].

Актуализация своего запаса знаний и концентрация субъективных трудностей в тестовых действиях: преподаватели организуют подготовку студентов к самостоятельному выполнению тестового учебного действия:

1. актуализация знаний, полученных ранее, что достаточно для организации нового курса действий;

2. тренировка соответствующих мыслительных операций. В конце этого этапа возникает индивидуальная активность учащихся, которая регистрируется самостоятельно.

Определение точки и основы сложности - инструкторы организуют идентификацию точки и основы сложности:

1. воссоздание выполненных операций и регистрация точки, в которой начались трудности;

2. выявление причин, стоящих за трудностями, при решении конкретной проблемы. 
Построение алгоритма для устранения трудностей: инструкторы организуют процесс открытия новых знаний, где учащиеся в коммуникативной форме разрабатывают алгоритм для будущих учебных действий: они ставят цель, создают план для достижения цели и находят решение к проблемной ситуации.

Системно-деятельностный подход реализуется с помощью следующих технологий:

- Информационные и коммуникационные технологии (межличностное общение)

- Технология, основанная на создании учебной ситуации (решение проблем, которые практически важны для изучения окружающего нас мира)

- Технологии, основанные на реализации проектной деятельности

- Технология, основанная на стратифицированной дифференциации обучения

- Активность подход технологии

Реализация построенного проекта: инструкторы организуют обсуждение различных вариантов, предложенных учащимися; выбирая лучший вариант.

Независимая работа с самооценкой на основе шаблона: преподаватели организуют самостоятельное выполнение учащимся упражнений на нестандартных решениях (курс действий) и самостоятельно проверяют выполнение задания на основе сравнения с шаблоном. Это создает, когда это возможно, успешную ситуацию для каждого студента [9].

Включение в изучение и пересмотр новых знаний и воспроизведение учебного материала имеют решающее значение для обеспечения непрерывности контента.

Размышляя об учебной деятельности: инструкторы организуют для учащихся оценку их деятельности, уточнение трудностей, возникающих в классе, как ориентацию предстоящей учебной деятельности, разбивку и выполнение самостоятельных рабочих заданий студента [10].

При реализации системно-деятельностного подхода существует ориентация на осознание учащимися своего самоопределения при системном обучении академиче- ским дисциплинам и выбор элективных дисциплин для профессионального роста с чувством уверенности в себе и своей деятельности.

Системно-деятельностный подход в образовании позволяет полностью обеспечить подготовку бакалавров и магистров в соответствии с требованиями Федеральных государственных образовательных стандартов высшего профессионального образования.

Системно-деятельностный подход - это подход, при котором учащийся не приобретает знания в готовом виде, а самостоятельно их усваивает в процессе своей учебно-познавательной деятельности. По словам А. Дистервега, «конечной целью любого воспитания является укрепление самостоятельности посредством самостоятельной деятельности».

При реализации системно-деятельностного подхода существует ориентация на осознание учащимися своего самоопределения в системном обучении академическим дисциплинам и выбор элективных дисциплин для профессионального роста с чувством уверенности в себе и своей деятельности.

Системно-деятельностный подход в образовании позволяет полностью обеспечить подготовку бакалавров и магистров в соответствии с требованиями Федеральных государственных образовательных стандартов высшего профессионального образования.

Системно-деятельностный подход - это подход, при котором учащийся не приобретает знания в готовом виде, а самостоятельно обретает их в процессе своей учебно-познавательной деятельности. По словам А. Дистервега, «конечной целью любого воспитания является укрепление самостоятельности посредством самостоятельной деятельности».

Мы считаем объединение деятельностного и компетентностного подходов позволяет основательно подойти к формированию компетенций выпускника, что, в свою очередь, обеспечивает не только приобретение знаний и умений, но и овладение необходимыми для будущей профессиональной деятельности качествами личности [11].

ЛИТЕРАТУРА

1. Шибечи P.A. и JP Jr. Riley, 1986. Влияние образования и восприятия студентов на отношение и достижения науки. Журнал исследований в области преподавания естественных наук, 23: 177-187.

2. Ранни, М., 1996. Индивидуально-ориентированные и модельно-ориентированные подходы к согласованности: измерение для рассмотрения человеческой рациональности. Вивек, ежеквартально в искусственном интеллекте, 9: 35-43

3. Ланкина М.П., 1998. Одна учебно-исследовательская проблема для студентов-физиков. Вестник Омского университета. 1 (7): 26-28

4. Хуторской А.В. Ключевые компетенции и образовательные стандарты. Дата просмотров 21.06.2012. www.eidos.ru/journal/2002/0423.htm 
5. Хуторской А.В., 2001. Современная дидактика. СПб .: Питер.

6. Мур Р.Л., К.Л. Кливленд и Х.А. Герш, 1978. Самозахват электронов в идеальных газах. Phys.Rev., 18 (3): 1183-1197.

7. Хеллер, П. и М. Холлабо, 1992. Обучение решению проблем посредством совместной группировки. Часть 2. Проектирование задач и структурирование групп. Американский журнал физики, 60 (7): 637-644.

8. Нейман Ю., Лейбовиц Л., Шварц Б., 2000. Модели словесной медиации при решении задач: последовательный анализ самообъяснения. Журнал экспериментального образования, 68 (3): 197-213.

9. Палинксар, А.С. и А.Л. Браун, 1984. Взаимное учение о деятельности, способствующей пониманию и мониторингу понимания. Познание и обучение, $1(2): 117-175$.

10. Крючева Я.В., Гаврилюк Н.П. Деятельностный и компетентностный подходы в образовании: успешность в интеграции. // Профессиональное образование в современном мире. 2016;6(3):421-427.

(с) Карасева Эльмира Миндыхатовна (elmira___@mail.ru), Карасева Венера Миндыхатовна.

Журнал «Современная наука: актуальные проблемы теории и практики»

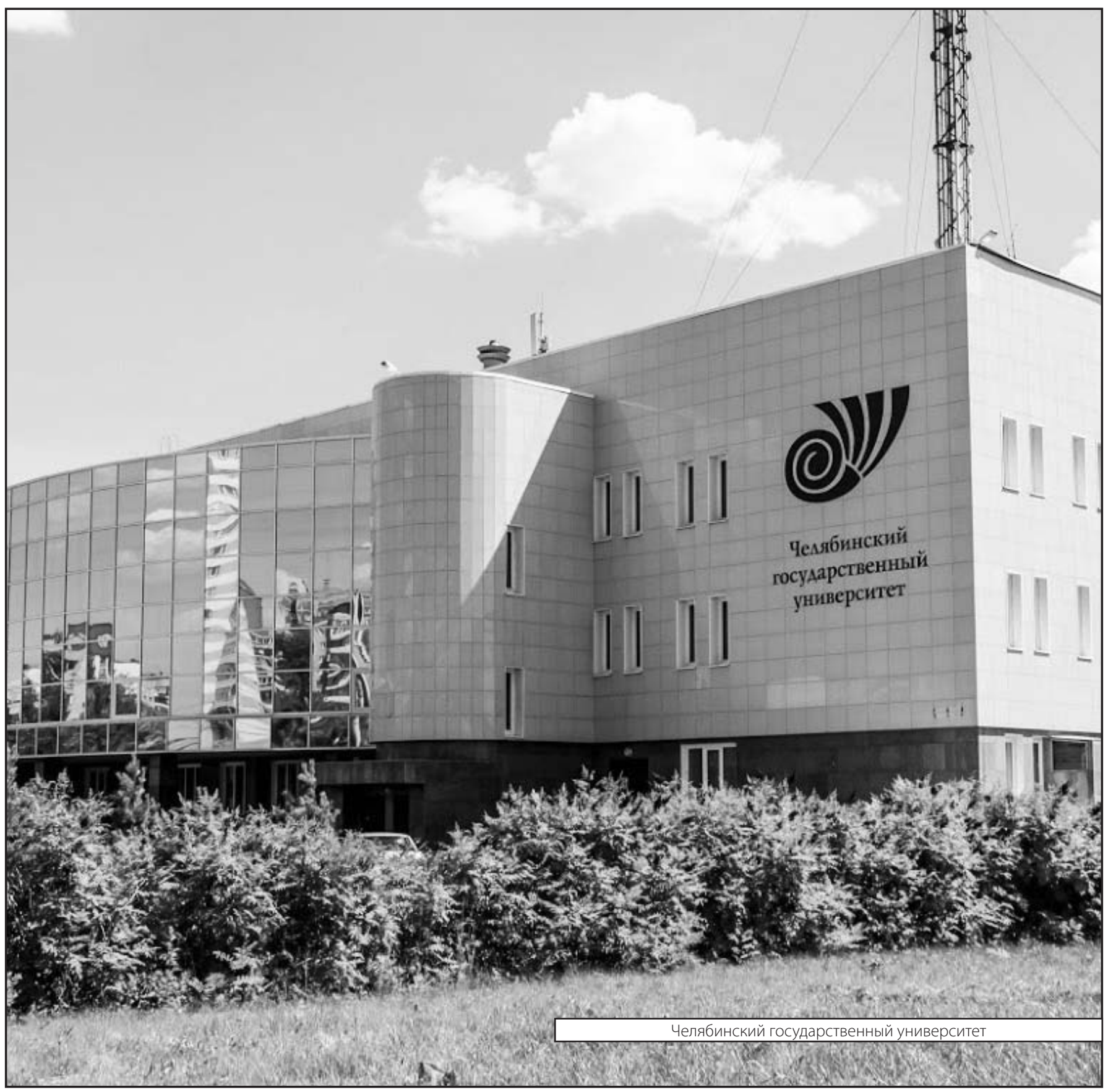

